\title{
PREDIKSI JUMLAH TANGKAP IKAN DI PELABUHAN PERIKANAN NUSANTARA BRONDONG MENGGUNAKAN FUZZY TIME SERIES MODEL CHEN
}

\author{
Imamatul Ummah ${ }^{1}$, Nailul Izzati ${ }^{2}$ \\ Fakultas Teknik Universitas Hasyim Asy`ari Tebuireng Jombang

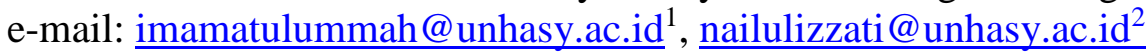

\begin{abstract}
Abstrak
Berdasarkan data jumlah tangkap ikan di Pelabuhan Perikanan Nusantara (PPN) Brondong, menunjukkan bahwa rata-rata jumlah tangkap ikan selama 11 tahun terakhir sejumlah 65017 ton pertahun. Pada tahun 2016 jumlah tangkap ikan sebesar 66179 ton dan terjadi kenaikan yang sangat signifikan pada tahun 2017 sejumlah 130742 ton. Data tersebut jelas sangat mengkhawatirkan, karena terjadi overfishing yang dapat mengakibatkan populasi ikan semakin berkurang. Pada penelitian ini dilakukan prediksi jumlah tangkap ikan yang ada di Pelabuhan Perikanan Nusantara (PPN) Brondong guna mengontrol jumlah tangkap ikan, untuk membantu program pemerintah dalam mengelola hasil laut. Pada penelitian ini menggunakan metode fuzzy time series model Chen, karena data tangkap ikan terkait dengan musim. Hasil prediksi menunjukkan tingkat error sebesar $28 \%$.

Kata Kunci: Pelabuhan Perikanan Nusantara Brondong, Prediksi Jumlah Tangkap Ikan, Fuzzy Time
\end{abstract} Series Model Chen

\section{Abstract}

Based on the data of Brondong National Fishing Port, the average number of fish caught for the last 11 years is 65017 tons per year. In 201666179 tons of fishes use caught and there was a very significant increase in 2017 that is of 130742 tons. The data it is clearly very worrying because of overfishing can cause decreasing of the fish population to decrease. In this study predictions of the number of fish caught in Brondong National Fishing Port are predicted, to assist gonvernment programs in managing marine resource. The method used in this study is fuzzy time series model Chen, as the data are related to the season. The accuracy of the prediction is $72 \%$.

Keyword: Brondong National Fishing Port, Prediction of the amount of fish caught, Fuzzy Time Series Chen Model

\section{PENDAHULUAN}

Potensi di Indonesia sangat besar dalam sektor perikanan dan kelautan. Hasil tangkap ikan di perairan umum mencapai 54 juta hektar dengan potensi produksi 0,9 juta ton/tahun. Salah satu aktivitas tangkap ikan yang sudah melebihi batas berada di laut Jawa, menurut Hazliansyah (2015) masyarakat di sekitar laut Jawa memanfaatkan potensi ikan mencapai $95 \%$. Hal tersebut jelas sangat merugikan bagi keberlangsungan ekosistem laut dan penikmat ikan dimasa mendatang.

Pemerintah melalui programnya melarang penggunaan alat tangkap pukat hela dan pukat tarik. Hal tersebut dilakukan guna menghindari kerusakan ekosistem ikan, sehingga sumber daya ikan tetap berlanjut hingga masa mendatang. Salah satu laut Jawa yang masih menggunakan alat tangkap ikan pukat tarik berkapal adalah PPN Brondong. Berdasarkan data PPN Brondong hasil tangkap ikan tahun 2017, rata-rata ikan yang diperoleh menggunakan alat tangkap dogol adalah 5153 ton.

Saat ini penelitian tentang hasil tangkap ikan masih terus berlanjut, guna membantu program pemerintah dalam menjaga sumber daya ikan. Beberapa penelitian seperti; 1) Mennofatria Boer dan Kiagus Abdul Aziz (2007) mengkaji stok ikan untuk dapat memperkirakan seberapa banyak ikan yang harus ditangkap, 2) Farizi Rachman dan R.A. Nooromadani Yuniati (2017) mengcluster potensi sektor perikanan laut sebagai acuan pemerintah dalam merancang kebijakan sesuai dengan potensi perikanan laut dan 3) Andi Alamsyah Rivai (2017) menganalisis spasial dan temporal pada perikanan agan perahu untuk 
memberikan informasi terkait distribusi ikan, pola kebiasaan penangkapan ikan dan tekanan penangkapan ikan.

Sedangkan beberapa penelitian terkait prediksi yaitu 1) memprediksi lokasi daerah penangkapan ikan (Kunarso, 2016) dan 2) membandingkan model Chen dengan Lee untuk memprediksi jumlah ikan (Tamrin, 2018). Pada penelitian ini memperdiksi hasil jumlah tangkap ikan di PPN Brondong, untuk dapat mengontrol jumlah tangkap ikan yang seharusnya didapat. Sehingga potensi sumber daya ikan tetap terjaga dan membantu program pemerintah dalam melestarikan sumber daya ikan.

Data tangkap ikan merupakan data yang berurutan menurut waktu. Hasil tangkap ikan juga dipengaruhi oleh faktor iklim, sehingga pada bulan-bulan tertentu hasil ikan akan mengalami kenaikan dan penurunan. Oleh karena itu, metode yang digunakan pada penelitian ini adalah fuzzy time series model Chen.

\section{METODE PENELITIAN}

a. Fuzzy Time Series

Konsep prediksi fuzzy time series adalah menggunakan data terdahulu untuk memprediksi data yang akan datang. Jika $Y(t)(t=\cdots, 0,1,2, \ldots)$ adalah himpunan bagian dari $R$, misalkan $Y(t)$ adalah himpunan semesta yang dideskripsikan oleh himpunan fuzzy $\mu_{i}(t)$. Jika $F(t)$ terdiri dari $\mu_{i}(t)(i=1,2, \ldots), F(t)$ disebut sebuah fuzzy time series pada $Y(t) \quad$ (S.M Chen,1996).

Langkah awal yang sangat penting pada proses fuzzy time series adalah penentuan panjang interval yang harus digunakan. Terdapat beberapa macam metode dalam penentuan panjang interval yaitu automatic clustering dan average based. Pada penelitian ini menggunakan metode average based sebagai penentuan panjang interval.

Proses metode average based yaitu;

1. Hitung semua selisih (lag) absolute

$\sum_{i=1}^{n-1}\left|D_{i+1}-D_{i}\right|$

Dengan $D_{i}(i=1,2, \ldots, n-1)$
2. Hasil penjumlahan tersebut, dijumlahkan kemudian dibagi dengan banyaknya data (rumus mean)

3. Hasil mean dibagi dengan dua untuk diperoleh panjang interval. Panjang interval tersebut dapat digunakan untuk menentukan batas interval pada proses universe of discourse

(Xihao dkk, 2008).

Setelah memperoleh panjang interval, selanjutnya adalah proses fuzzy time series.

1. Pembentukan $U$ (Universe of Discourse)

$\frac{D_{\max }-D_{\min }}{\text { panjang interval }}$

Dengan $D_{\max }$ adalah data terbesar dan $D_{\text {min }}$ adalah data terkecil. Sehingga hasil dari pembentukan $U=$ $\left\{U_{1}, U_{2}, \ldots, U_{n}\right\}$, yang kemudian dapat dituliskan dalam bentuk $U_{1}=$ $\left[D_{\text {min }}, X_{1}\right], U_{2}=\left[X_{1}, X_{2}\right], \ldots, U_{N}=$ $\left[X_{n-1}, D_{\text {max }}\right]$ dengan $X_{1}<X_{2}<\cdots<$ $X_{n-1}$

2. Pembentukan himpunan fuzzy

Misalkan $U$ adalah semesta pembicaraan, dengan $U=$ $\left\{U_{1}, U_{2}, \ldots, U_{n}\right\}$, maka himpunan fuzzy $A_{i}$ dari $U$ adalah $A_{i}=\frac{f_{A_{I}\left(U_{1}\right)}}{U_{1}}+$ $\frac{f_{A_{I}}\left(U_{2}\right)}{U_{2}}+\cdots+\frac{f_{A_{I}}\left(U_{n}\right)}{U_{n}}$. Nilai

keanggotaan dari $f_{A_{i}}$ adalah

$$
a_{i j}=\left\{\begin{aligned}
1 & \text { if } i=j \\
0,5 & \text { if } j=i-1 \text { atau } i+1 \\
0 & \text { yang lainnya }
\end{aligned}\right.
$$

Sehingga diperoleh matrikas himpunan fuzzy $a_{i j}$

Tabel 1. Matriks Himpunan Fuzzy $a_{i j}$

\begin{tabular}{|c|c|c|c|c|}
\hline$a$ & 1 & 2 &.. & $i$ \\
\hline 1 & 1 & 0,5 & 0 & 0 \\
\hline 2 & 0,5 & 1 & 0,5 & 0 \\
\hline$\vdots$ & 0 & 0,5 & 1 & 0,5 \\
\hline$j$ & 0 & 0 & 0,5 & 1 \\
\hline
\end{tabular}

Berdasarkan matriks tersebut dapat dituliskan kembali dalam himpunan fuzzy sebagai berikut;

$$
\begin{aligned}
& A_{1}=\frac{a_{11}}{U_{1}}+\frac{a_{12}}{U_{2}}+\frac{a_{13}}{U_{3}}+. .+\frac{a_{1 n}}{U_{n}} \\
& A_{2}=\frac{a_{21}}{U_{1}}+\frac{a_{22}}{U_{2}}+\frac{a_{23}}{U_{3}}+. .+\frac{a_{2 n}}{U_{n}}
\end{aligned}
$$




$$
A_{n}=\frac{a_{k 1}}{U_{1}}+\frac{a_{k 2}}{U_{2}}+\frac{a_{k 3}}{U_{3}}+. .+\frac{\mathrm{a}_{\mathrm{kn}}}{\mathrm{U}_{\mathrm{n}}}
$$

3. Pembentukan fuzzy logic relationship Pada langkah ini dibentuk aturan if $F(t)$ then $Y(t)$, dimana $F(t)$ terdiri dari $U_{I}(t)(i=1,2, \ldots, n)$ dan $Y(t)$ adalah himpunan semesta dari himpunan fuzzy $U_{I}(t)$.

4. Pembentukan Fuzzy Logic Relationship Group (FLRG)

Pada proses ini terdapat beberapa model yang bisa digunakan, seperti model Song dan Chisson, model Chen, dan model Lee. Pada penelitian ini menggunakan model Chen. Proses kerja model Chen adalah hasil dari fuzzy logic relationship dikelompokkan dalam current state dan next state. Dimana current state merupakan $F(t)$, jika nilai $t$ sama maka akan dianggap menjadi satu dan next state adalah $Y(t)$ dikelompokkan dengan $F(t)$ yang memiliki nilai $t$ sama.

\section{HASIL DAN PEMBAHASAN}

Proses fuzzy time series model Chen untuk prediksi jumlah tangkap ikan di pelabuhan brondong melalui empat tahap yaitu pembentukan $\mathrm{U}$ (universe of discourse), pembentukan fuzzyfication, pembentukan fuzzy logic relationship, dan pembentukan fuzzy logic relationship group model Chen. Sebelum pembentukan $\mathrm{U}$ (universe of discourse), ditentukan terlebih dahulu interval $U$ yang akan digunakan. Dalam penelitian ini, pembentukan interval menggunakan metode average based.

1. Penentuan Interval Menggunakan Metode Average Based

Langkah pertama dalam metode average based yaitu menghitung selisih absolute tiap data menggunakan rumus 1 , sehingga diperoleh pada tabel 2.

Tabel 2. Data Jumlah Tangkap Ikan

\begin{tabular}{|l|c|c|}
\hline $\begin{array}{c}\text { BULAN - } \\
\text { TAHUN }\end{array}$ & $\begin{array}{c}\text { JUMLAH } \\
\text { TANGKAP } \\
\text { IKAN (TON) }\end{array}$ & SELISIH \\
\hline Januari 2007 & 4369 & 215 \\
\hline Februari 2007 & 4584 & 395 \\
\hline Maret 2007 & 4979 & 410 \\
\hline April 2007 & 5389 & 254 \\
\hline
\end{tabular}

\begin{tabular}{|l|c|c|}
\hline$\ldots$ & $\ldots$ & $\ldots$ \\
\hline Oktober 2017 & 16160 & 1586 \\
\hline November 2017 & 14574 & 5410 \\
\hline Desember 2017 & 9164 & - \\
\hline
\end{tabular}

Langkah kedua menghitung rata-rata dari selisih absolute tiap data yang sudah dihitung sebelumnya menggunakan rumus mean.

$\begin{aligned} \text { Mean }= & \frac{181288}{131} \\ & =1384\end{aligned}$

Langkah ketiga yaitu hasil mean dibagi dengan 2 untuk memperoleh panjang interval, sehingga diperoleh 692. Hasil panjang interval ini akan digunakan untuk menentukan batas interval pada setiap $U_{n}$.

2. Tahapan fuzzy time series model Chen Langkah pertama pembentukan $\mathrm{U}$ (universe of discourse)

Berdasarkan data jumlah tangkap ikan perbulan selama tahun 2007 - 2017 di pelabuhan brondong, jumlah minimal hasil tangkap ikan adalah 1764 ton dan nilai maksimal 16160 ton. Banyaknya U yang terbentuk adalah 21, diperoleh dari selisih jumlah hasil tangkap ikan dibagi dengan panjang interval $\frac{16160-1764}{692}=21$. Sehingga dapat ditulis sebagai berikut;

$U_{1}=[1764,2456], U_{2}$

$=[2456,3148], U_{3}$

$=[3148,3840]$,

$U_{4}=[3840,4532], U_{5}$ $=[4532,5224], U_{6}$

$=[5224,5916]$,

$U_{7}=[5916,6608], U_{8}$ $=[6608,7300], U_{9}$

$=[7300,7992]$,

$U_{10}=[7992,8684], U_{11}$ $=[8684,9376], U_{12}$ $=[9376,10068]$,

$U_{13}=[10068,10760], U_{14}$ $=[10760,11452], U_{15}$ $=[11452,12144]$,

$U_{16}=[12144,12836], U_{17}$ $=[12836,13528], U_{18}$ $=[13528,14220]$,

$U_{19}=[14220,14912], U_{20}$ $=[14192,14604], U_{21}$ $=[14604,14296]$ 
Langkah kedua pembentukan fuzzyfication Pada langkah ini dibentuk sebuah matriks berukuran $n \times n$, dengan $n$ sebanyak 21 dan disederhanakan menggunakan nilai keanggotaan dari himpunan fuzzy yaitu

$$
a_{i j}=\left\{\begin{aligned}
1 & \text { if } i=j \\
0,5 & \text { if } j=i-1 \text { atau } i+1 \\
0 & \text { yang lainnya }
\end{aligned}\right.
$$

Tabel 3. Matriks Himpunan Fuzzy

\begin{tabular}{|c|c|c|c|c|c|c|c|c|c|c|c|c|c|c|c|c|c|c|c|c|c|}
\hline$a_{i j}$ & 1 & 2 & 3 & 4 & 5 & 6 & 7 & 8 & 9 & 10 & 11 & 12 & 13 & 14 & 15 & 16 & 17 & 18 & 19 & 20 & 21 \\
\hline 1 & 1 & 0.5 & 0 & 0 & 0 & 0 & 0 & 0 & 0 & 0 & 0 & 0 & 0 & 0 & 0 & 0 & 0 & 0 & 0 & 0 & 0 \\
\hline 2 & 0.5 & 1 & 0.5 & 0 & 0 & 0 & 0 & 0 & 0 & 0 & 0 & 0 & 0 & 0 & 0 & 0 & 0 & 0 & 0 & 0 & 0 \\
\hline 3 & 0 & 0.5 & 1 & 0.5 & 0 & 0 & 0 & 0 & 0 & 0 & 0 & 0 & 0 & 0 & 0 & 0 & 0 & 0 & 0 & 0 & 0 \\
\hline 4 & 0 & 0 & 0.5 & 1 & 0.5 & 0 & 0 & 0 & 0 & 0 & 0 & 0 & 0 & 0 & 0 & 0 & 0 & 0 & 0 & 0 & 0 \\
\hline 5 & 0 & 0 & 0 & 0.5 & 1 & 0.5 & 0 & 0 & 0 & 0 & 0 & 0 & 0 & 0 & 0 & 0 & 0 & 0 & 0 & 0 & 0 \\
\hline 6 & 0 & 0 & 0 & 0 & 0.5 & 1 & 0.5 & 0 & 0 & 0 & 0 & 0 & 0 & 0 & 0 & 0 & 0 & 0 & 0 & 0 & 0 \\
\hline 7 & 0 & 0 & 0 & 0 & 0 & 0.5 & 1 & 0.5 & 0 & 0 & 0 & 0 & 0 & 0 & 0 & 0 & 0 & 0 & 0 & 0 & 0 \\
\hline 8 & 0 & 0 & 0 & 0 & 0 & 0 & 0.5 & 1 & 0.5 & 0 & 0 & 0 & 0 & 0 & 0 & 0 & 0 & 0 & 0 & 0 & 0 \\
\hline 9 & 0 & 0 & 0 & 0 & 0 & 0 & 0 & 0.5 & 1 & 0.5 & 0 & 0 & 0 & 0 & 0 & 0 & 0 & 0 & 0 & 0 & 0 \\
\hline 10 & 0 & 0 & 0 & 0 & 0 & 0 & 0 & 0 & 0.5 & 1 & 0.5 & 0 & 0 & 0 & 0 & 0 & 0 & 0 & 0 & 0 & 0 \\
\hline 11 & 0 & 0 & 0 & 0 & 0 & 0 & 0 & 0 & 0 & 0.5 & 1 & 0.5 & 0 & 0 & 0 & 0 & 0 & 0 & 0 & 0 & 0 \\
\hline 12 & 0 & 0 & 0 & 0 & 0 & 0 & 0 & 0 & 0 & 0 & 0.5 & 1 & 0.5 & 0 & 0 & 0 & 0 & 0 & 0 & 0 & 0 \\
\hline 13 & 0 & 0 & 0 & 0 & 0 & 0 & 0 & 0 & 0 & 0 & 0 & 0.5 & 1 & 0.5 & 0 & 0 & 0 & 0 & 0 & 0 & 0 \\
\hline 14 & 0 & 0 & 0 & 0 & 0 & 0 & 0 & 0 & 0 & 0 & 0 & 0 & 0.5 & 1 & 0.5 & 0 & 0 & 0 & 0 & 0 & 0 \\
\hline 15 & 0 & 0 & 0 & 0 & 0 & 0 & 0 & 0 & 0 & 0 & 0 & 0 & 0 & 0.5 & 1 & 0.5 & 0 & 0 & 0 & 0 & 0 \\
\hline 16 & 0 & 0 & 0 & 0 & 0 & 0 & 0 & 0 & 0 & 0 & 0 & 0 & 0 & 0 & 0.5 & 1 & 0.5 & 0 & 0 & 0 & 0 \\
\hline 17 & 0 & 0 & 0 & 0 & 0 & 0 & 0 & 0 & 0 & 0 & 0 & 0 & 0 & 0 & 0 & 0.5 & 1 & 0.5 & 0 & 0 & 0 \\
\hline 18 & 0 & 0 & 0 & 0 & 0 & 0 & 0 & 0 & 0 & 0 & 0 & 0 & 0 & 0 & 0 & 0 & 0.5 & 1 & 0.5 & 0 & 0 \\
\hline 19 & 0 & 0 & 0 & 0 & 0 & 0 & 0 & 0 & 0 & 0 & 0 & 0 & 0 & 0 & 0 & 0 & 0 & 0.5 & 1 & 0.5 & 0 \\
\hline 20 & 0 & 0 & 0 & 0 & 0 & 0 & 0 & 0 & 0 & 0 & 0 & 0 & 0 & 0 & 0 & 0 & 0 & 0 & 0.5 & 1 & 0.5 \\
\hline 21 & 0 & 0 & 0 & 0 & 0 & 0 & 0 & 0 & 0 & 0 & 0 & 0 & 0 & 0 & 0 & 0 & 0 & 0 & 0 & 0.5 & 1 \\
\hline
\end{tabular}

Berdasarkan tabel 3. Diperoleh himpunan

$$
\begin{aligned}
& A_{1}=\frac{1}{U_{1}}+\frac{0,5}{U_{2}}+\frac{0}{U_{3}}+\frac{0}{U_{4}}+. .+\frac{0}{U_{19}}+ \\
& \frac{0}{U_{20}}+\frac{0}{U_{21}} \\
& A_{2}=\frac{0,5}{U_{1}}+\frac{1}{U_{2}}+\frac{0,5}{U_{3}}+\frac{0}{U_{4}}+. .+\frac{0}{U_{19}}+ \\
& \frac{0}{U_{20}}+\frac{0}{U_{21}} \\
& A_{20}=\frac{0}{U_{1}}+\frac{0}{U_{2}}+\frac{0}{U_{3}}+\frac{0}{U_{4}}+. .+\frac{0,5}{U_{19}}+ \\
& \frac{1}{U_{20}}+\frac{0,5}{U_{21}} \\
& \begin{aligned}
A_{21}= & \frac{0}{U_{1}}+\frac{0}{U_{2}}+\frac{0}{U_{3}}+\frac{0}{U_{4}}+. .+\frac{0}{U_{19}}+ \\
& \frac{0,5}{U_{20}}+\frac{1}{U_{21}}
\end{aligned}
\end{aligned}
$$


Tabel 4. Fuzzy Logic Relationship

\begin{tabular}{|c|c|c|c|}
\hline BULAN TAHUN & $\begin{array}{c}\text { JUMLAH TANGKAP IKAN } \\
\text { (TON) }\end{array}$ & FUZZYFICATION & RELATIONSHIP \\
\hline Januari 2007 & 4369 & $A_{4}$ & \\
\hline Februari 2007 & 4584 & $A_{5}$ & $A_{4} \rightarrow A_{5}$ \\
\hline Maret 2007 & 4979 & $A_{5}$ & $A_{5} \rightarrow A_{5}$ \\
\hline$\ldots$ & $\ldots$ & $\ldots$ & $\ldots$ \\
\hline Oktober 2017 & 16160 & $A_{21}$ & $A_{14} \rightarrow A_{21}$ \\
\hline November 2017 & 14574 & $A_{19}$ & $A_{21} \rightarrow A_{19}$ \\
\hline Desember 2017 & 9164 & $A_{11}$ & $A_{19} \rightarrow A_{21}$ \\
\hline
\end{tabular}

Langkah keempat pembentukan fuzzy logic relationship model Chen

Berdasarkan tabel 5 diperoleh prediksi jumlah tangkap ikan perbulan di pelabuhan brondong sebagai berikut;

Fuzzy time series model Chen yaitu semua hasil fuzzy logic relationship dikelompokkan dengan memperhatikan $A_{i}$ sebagai current state dan $A_{j}$ sebagai next state, seperti yang ditunjukkan tabel 5 berikut.

Tabel 5. Fuzzy Logic Relationship Group Model Chen

\begin{tabular}{|l|l|r|}
\hline \multicolumn{1}{|c|}{$\begin{array}{l}\text { CURRENT } \\
\text { STATE }\end{array}$} & \multicolumn{1}{|c|}{ NEXT STATE } & FORCASTING \\
\hline A1 & A1,A3,A4,A6 & 3840 \\
\hline A2 & A1,A3,A4,A5,A7 & 4186 \\
\hline A3 & A1,A2,A3,A4,A6,A7 & 4071 \\
\hline A4 & A2,A3,A4,A5,A6,A7 & 4532 \\
\hline A5 & A3,A4,A5,A6,A7,A9, & 5768 \\
\hline A6 & A10 & 5224 \\
\hline A7 & A9,A19 & \\
\hline A8 & A1,A3,A4,A5,A6,A7, & 5138 \\
\hline A9 & A8,A9 & 5743 \\
\hline A10 & A2,A6,A7,A10 & 6262 \\
\hline A14 & A2,A6,A8,A9,A10 & 6954 \\
\hline A15 & A7,A9 & 14912 \\
\hline A18 & A18,A21 & 9030 \\
\hline A19 & A8,A14 & 10414 \\
\hline A21 & A10 & 14566 \\
\hline
\end{tabular}

\begin{tabular}{|c|c|c|}
\hline $\begin{array}{l}\text { BULAN } \\
\text { TAHUN }\end{array}$ & $\begin{array}{c}\text { JUMLAH } \\
\text { TANGKAP } \\
\text { IKAN } \\
\text { (TON) }\end{array}$ & PREDIKSI \\
\hline Januari 2007 & 4369 & - \\
\hline Februari 2007 & 4584 & 4532 \\
\hline Maret 2007 & 4979 & 5768 \\
\hline April 2007 & 5389 & 5768 \\
\hline $\begin{array}{ll}\ldots & 1\end{array}$ & $\ldots$ & $\ldots$ \\
\hline Oktober 2017 & 16160 & 14912 \\
\hline $\begin{array}{l}\text { November } \\
2017\end{array}$ & 14574 & 14566 \\
\hline $\begin{array}{l}\text { Desember } \\
2017\end{array}$ & 9164 & 10414 \\
\hline
\end{tabular}

3. Menghitung Mean Absolute Percent Error (MAPE)

Perhitungan MAPE bertujuan untuk mengetahui berapa persen error prediksi yang dilakukan dengan fuzzy time series model Chen, dengan menghitung percent error dari setiap data kemudian dihitung rata-ratanya diperoleh $28 \%$.

4. KESIMPULAN

Prediksi yang dilakukan dengan fuzzy time series model Chen, dengan menghitung MAPE diperoleh 28\%. Artinya prediksi jumlah tangkap ikan perbulan di pelabuhan brondong menggunakan fuzzy time series model Chen, sudah cukup baik dengan tingkat errornya sebesar $28 \%$. 


\section{DAFTAR PUSTAKA}

Boer, Mennofatria., \& Kiagus Abdul Aziz. 2007. Rancangan Pengambilan Contoh Upaya Tangkap Ikan dan Hasil Tangkap Ikan Untuk Pengkajian Stok Ikan. Jurnal Ilmu-Ilmu Perairan dan Perikanan Indonesia, Desember 2007, Jilid 14. Nomor 2: $67-71$.

Chen, S.M.1996. Forcasting Enrollments Based On Fuzzy Time Series. Fuzzy Sets and System, 81:311-319.

Hazliansyah. 24 Maret, 2015. Pemanfaatan Potensi Ikan Laut Jawa Melebihi Batas, (Online), (https://www.republika.co.id/berita/nasiona 1/daerah/15/03/24/nlpkty-pemanfaatanpotensi-ikan-laut-jawa-melebihi-batas, diakses 28 Agustus 2018)

Kunarso., dkk, 2016. Musim Ikan Di Perairan Laut Jawa Kabupaten Jepara dan Prediksi Lokasi Fishing Ground-nya. Prosiding Seminar Nasional Tahunan Ke-V HasilHasil Penelitian Perikanan dan Kelautan, hlm. 636-646, Juni 2016.

Rachman, Farizi., \& R.A. Nooromadani Yuniati. 2017. Analisis Cluster Sektor Perikanan Laut dengan Menggunakan Fuzzy K-Means. Seminar MASTER 2017, ISSN : 2548-1509 (cetak) | 2548-6527 (online).

Rivai, Andi Alamsyah., dkk. 2017. Pemetaan Daerah Potensial Penangkapan Ikan Menggunakan - Pendekatan Model GIS HOTSPOT dan Analisis Time Series Studi Kasus Pada Perikanan Bagan Perahu Di Kepulauan Seribu. Jurnal Ilmu dan Teknologi Kelautan Tropis, Vol. 9, No. 1, Hlm. 337-356, Juni 2017.

Tamrin, Hairul., Junaidi Noh., \& Sahriar Hamzah. 2018. Perbandingan Model Chen dan Model Lee Pada Metode Fuzzy Time Series untuk Prediksi Jumlah Ikan. Jurnal Teknologi Informatika (J-TIFA), Vol. 1, No. 1, ISSN:2654-2617 (cetak) | 2654-2633 (online), September 2018.

Tim Rekap Data PPN Brondong, Data Rekapitulasi Produksi Ikan Per Alat Tangkap Tahun 2017 Di PPN Brondong, PPN Brondong, 2017.

Xihao, S., Li Yimin. 2008. Average Based Fuzzy Time Series Models For Forecasting Shanghai Compound Index. Word Journal Of Modelling and Simulation. Vol. 4 pp. 104-111. 